\title{
Polymicrobial intensive care unit-acquired pneumonia: prevalence, microbiology and outcome
}

\author{
Miquel Ferrer ${ }^{1,2,3}$, Leonardo Filippo Difrancesco ${ }^{1,4}$, Adamantia Liapikou ${ }^{1,5}$, Mariano Rinaudo ${ }^{1}$, Marco Carbonara ${ }^{1,6}$, \\ Gianluigi Li Bassi ${ }^{1,2,3}$, Albert Gabarrus ${ }^{1,2}$ and Antoni Torres ${ }^{1,2,3^{*}}$
}

\begin{abstract}
Background: Microbial aetiology of intensive care unit (ICU)-acquired pneumonia (ICUAP) determines antibiotic treatment and outcomes. The impact of polymicrobial ICUAP is not extensively known. We therefore investigated the characteristics and outcomes of polymicrobial aetiology of ICUAP.

Method: Patients with ICUAP confirmed microbiologically were prospectively compared according to identification of 1 (monomicrobial) or more (polymicrobial) potentially-pathogenic microorganisms. Microbes usually considered as non-pathogenic were not considered for the etiologic diagnosis. We assessed clinical characteristics, microbiology, inflammatory biomarkers and outcome variables.

Results: Among 441 consecutive patients with ICUAP, 256 (58 \%) had microbiologic confirmation, and 41 (16\%) of them polymicrobial pneumonia. Methicillin-sensitive Staphylococcus aureus, Haemophilus influenzae, and several Enterobacteriaceae were more frequent in polymicrobial pneumonia. Multi-drug and extensive-drug resistance was similarly frequent in both groups. Compared with monomicrobial, patients with polymicrobial pneumonia had less frequently chronic heart disease (6, $15 \%$ vs. $71,33 \%, p=0.019)$, and more frequently pleural effusion $(18,50 \%$, vs. 54, $25 \%, p=0.008)$, without any other significant difference. Appropriate empiric antimicrobial treatment was similarly frequent in the monomicrobial $(185,86 \%)$ and the polymicrobial group (39, $95 \%)$, as were the initial response to the empiric treatment, length of stay and mortality. Systemic inflammatory response was similar comparing monomicrobial with polymicrobial ICUAP.

Conclusion: The aetiology of ICUAP confirmed microbiologically was polymicrobial in $16 \%$ cases. Pleural effusion and absence of chronic heart disease are associated with polymicrobial pneumonia. When empiric treatment is frequently appropriate, polymicrobial aetiology does not influence the outcome of ICUAP.
\end{abstract}

Keywords: Hospital-acquired pneumonia, ICU-acquired pneumonia, Ventilator-acquired pneumonia, Polymicrobial pneumonia

\section{Background}

Intensive care unit (ICU)-acquired pneumonia (ICUAP) is the leading infection in critically-ill patients, accounting for prolonged mechanical ventilation and length of stay, and poor outcome [1-4]. The use of inappropriate initial antibiotic therapy is a major determinant of

\footnotetext{
* Correspondence: ATORRES@clinic.ub.es

'Department of Pneumology, Thorax Institute, Hospital Clinic, Villarroel 170, 08036 Barcelona, Spain

${ }^{2}$ Institut d'Investigacions Biomèdiques August Pi I Sunyer (IDIBAPS),

Barcelona, Spain

Full list of author information is available at the end of the article
}

mortality in patients with ICUAP [5], emphasizing the importance of a timely and accurate therapy for this infection [6]. For this reason, it is often necessary to use a combination of broad-spectrum empiric antibiotics, particularly in patients who are at risk for difficult-to-treat bacteria [7, 8]. Recent investigations have shown that multi-drug-resistant (MDR) or high-risk pathogens have been isolated in around half of patients with an episode of ventilator-associated pneumonia (VAP) or ICUAP confirmed microbiologically $[9,10]$. 
ICUAP, and particularly VAP, can be caused by more than one microbial pathogen. Multiple etiologic pathogens are potentially an additional challenge for achieving appropriate antimicrobial treatment in these patients. A previous study reported a $48 \%$ rate of polymicrobial etiology in episodes of VAP with microbiologic confirmation [11]. These authors concluded that the epidemiology and outcomes of patients with monomicrobial and polymicrobial VAP did not differ significantly. However, in this study, a substantial proportion of episodes classified as polymicrobial VAP had positive isolation of bacteria usually considered as non-pathogenic microorganisms. Moreover, between $15 \%$ and $73 \%$ patients with an episode of ICUAP are not previously intubated $[2,12,13]$, namely non-ventilator ICUAP (NV-ICUAP).

To our knowledge, no previous studies have comprehensively assessed polymicrobial ICUAP strictly considering the identification of potentially pathogenic microorganisms (PPM). We have recently shown that positive microbiology is associated with worse outcomes in patients with clinical diagnosis of ICUAP [14]. Therefore, whether patients with polymicrobial etiology of ICUAP have different characteristics and outcomes to those with monomicrobial etiology is unknown. We therefore investigated the incidence, characteristics, risk factors, systemic inflammatory response and outcomes of polymicrobial, compared with monomicrobial, etiology of ICUAP.

\section{Methods}

\section{Study population}

The study was conducted between October 2004 and September 2013 in six medical and surgical ICUs, comprising 45 beds, at Hospital Clinic, Barcelona, Spain, an 800-bed university hospital. The investigators made daily rounds in each ICU. Patients older than 18 years, admitted to these ICUs for $48 \mathrm{~h}$ or more, with clinical diagnosis of ICUAP were consecutively enrolled in the study, and this being only the first episode, were analyzed. Exclusion criteria were: 1) severe immune suppression (neutropenia after chemotherapy or hematopoietic transplant, druginduced immune suppression in solid-organ transplant or cytotoxic therapy, and patients with human immunodeficiency virus) and 2) absence of microbiologic confirmation. The institution's Internal Review Board approved the study (Comite Etic d'Investigacio Clinica, registry number 2009/5427) and written informed consent was obtained from patients or their next of kin.

\section{Definition of pneumonia, microbiologic processing, and antimicrobial treatment}

Clinical diagnosis of ICUAP was based on clinical criteria: new or progressive radiological pulmonary infiltrate together with at least two of the following: temperature $>38{ }^{\circ} \mathrm{C}$ or $<36{ }^{\circ} \mathrm{C}$, leukocytosis $>12,000 /$ $\mathrm{mm}^{3}$ or leukopenia $<4,000 / \mathrm{mm}^{3}$, and purulent respiratory secretions $[1,15,16]$. Non-ventilated ICUAP was defined when patients acquired pneumonia after more than $48 \mathrm{~h}$ of ICU admission and without previous mechanical ventilation [2]. We considered VAP in patients with previous invasive mechanical ventilation for $48 \mathrm{~h}$ or more. Early-onset pneumonia was defined as occurring within the first 4 days of hospitalization [1].

The microbiologic evaluation included the collection of at least one lower respiratory tract sample: sputum in non-ventilated patients, tracheobronchial aspirates (TBAS) in intubated patients, and/or bronchoscopic [17] or blind bronchoalveolar lavage (BAL) [18], whenever possible, within the first $24 \mathrm{~h}$ of inclusion [19]. Bronchoscopic BAL and blind BAL were performed as previously described [19].

The same sampling method was performed on the third day if clinically indicated. Blood cultures and cultures from pleural fluid, if puncture was indicated, were also taken. Urinary antigens of Legionella pneumophila and Streptococcus pneumoniae were systematically collected. Microbiologic confirmation of pneumonia was defined by the presence of at least one PPM in respiratory samples above predefined thresholds $\left(\mathrm{BAL}>10^{4}\right.$, sputum or TBAS $>10^{5}$ colony-forming units $/ \mathrm{mL}$, respectively), in pleural fluid or in blood cultures if an alternative cause of bacteremia was ruled out $[20,21]$.

Drug resistance of pathogens was defined according to a recent report [22]. MDR pathogens were defined as acquired non-susceptibility to at least one agent in three or more antimicrobial categories. Extensive drug resistance (XDR) was defined as non-susceptibility to at least one agent in all but two or fewer antimicrobial categories (i.e., bacterial isolates remain susceptible to only one or two categories). Pan drug resistance (PDR) was defined as non-susceptibility to all agents in all antimicrobial categories. We considered methicillin-resistant Staphylococcus aureus (MRSA), and Enterobacteriaceae producing extended-spectrum $\beta$-lactamase as MDR pathogens [9].

Monomicrobial and polymicrobial pneumonia were defined when one and more than one PPM, respectively, were identified as etiologic agents at onset of pneumonia. Isolation of Candida spp, Streptococcus viridans, Staphylococcus epidermidis, Neisseria spp, Enterococcus spp, and Corynebacterium spp in lower respiratory tract samples were not considered etiologic agents.

The initial empiric antimicrobial treatment was administered according to local adaptation of the American Thoracic Society/Infectious Disease Society of America guidelines [1], based on the most frequently isolated PPM and their patterns of antimicrobial sensitivity in our institution, and subsequently revised according to the microbiologic results. The empirical antimicrobial treatment was 
considered appropriate when the isolated pathogens were susceptible in vitro to at least one of the antimicrobials administered at an adequate dose [8].

We assessed the initial response to treatment after 72 to $96 \mathrm{~h}$ of antimicrobial treatment, as previously described [23, 24]. Non-response was considered when at least one of the following criteria were present: 1) no improvement of the arterial $\mathrm{O}_{2}$ tension to inspired $\mathrm{O}_{2}$ fraction ratio or need for intubation because of pneumonia (defined as need for intubation after $24 \mathrm{~h}$ from the beginning of antibiotics); 2) persistence of fever (temperature $\left.\geq 38{ }^{\circ} \mathrm{C}\right)$ or hypothermia $\left(<35.5^{\circ} \mathrm{C}\right)$ together with purulent respiratory secretions; 3 ) increase in the pulmonary infiltrates on chest radiograph $\geq 50 \%$; or 4 ) occurrence of septic shock or multiple organ dysfunction syndrome, defined as three or more organ system failures not present on day 1 .

\section{Assessment of systemic inflammatory response}

We evaluated the serum levels of interleukin (IL)-6, IL-8, tumor necrosis factor-alpha (TNF-alpha), C-reactive protein, procalcitonin and mid-regional pro-adrenomedullin within the first $24 \mathrm{~h}$ after the diagnosis of pneumonia. All methods of these analyses have been recently described in detail $[25,26]$.

\section{Data collection}

All relevant data were collected at admission and at onset of pneumonia from the medical records and bedside flow charts, including laboratory, radiologic and microbiologic information. We calculated the acute physiology and chronic health evaluation (APACHE)-II score [27] and the simplified acute physiology score (SAPS)-II [28] on ICU admission. The simplified clinical pulmonary infectious score (CPIS) [29] and the sepsis-related organ failure assessment (SOFA) [30] scores were also evaluated on ICU admission and up to 9 days after the onset of pneumonia. Septic shock [31] and acute respiratory distress syndrome (ARDS) [32] were defined according to previously described criteria. Patients were followed until death or up to 90 days after the diagnosis of pneumonia.

\section{Outcome variables}

The outcomes of patients with monomicrobial pneumonia were compared to those with polymicrobial pneumonia. The primary outcome variable was mortality at 90 days after the diagnosis of ICUAP. Secondary outcomes included initial non-response to treatment, length of ICU and hospital stay, ventilator-free days at day 28 [33], and mortality at 28 days.

\section{Statistical analysis}

Categorical and continuous data are presented as number (percentage) and as mean \pm SD (or median (inter-quartile range)), respectively. Categorical variables were compared with the chi square $\left(\chi^{2}\right)$ test or the Fisher exact test. Quantitative continuous variables were compared using the $t$ test or the Mann-Whitney test for normally and non-normally distributed variables, respectively. Survival curves for patients with monomicrobial and polymicrobial pneumonia were obtained using the Kaplan-Meier method and compared using the log-rank test.

The association between polymicrobial or monomicrobial etiology and patients' outcomes was adjusted for variables potentially related to mortality, such as age, APACHE-II and SAPS scores at ICU admission, SOFA score, CPIS and arterial partial pressure of oxygen/inspired oxygen fraction $\left(\mathrm{PaO}_{2} / \mathrm{FiO}_{2}\right)$ ratio at onset of pneumonia, VAP or NV-ICUAP, and unilateral or bilateral chest $\mathrm{x}$-ray infiltrates. We used Cox proportional hazard regression analysis for 28-day and 90-day mortality.

All reported $P$ values are two-sided and not adjusted for multiple comparisons. A $P$ value $<0.05$ was considered significant. All statistical analyses were performed using IBM SPSS Statistics Version 20 (Armonk, NY, USA).

\section{Results}

\section{Patients' characteristics}

We prospectively identified 441 consecutive patients with ICUAP; 185 (42\%) were excluded because a positive microbiological diagnosis could not be made. Therefore, we included 256 patients: 215 (84 \%) with monomicrobial, and 41 (16\%) with polymicrobial ICUAP (Fig. 1).

The characteristics of patients at ICU admission and at onset of pneumonia are summarized in Tables 1 and 2. The rate of chronic heart disease was lower, and the rate of pleural effusion was higher, in patients with polymicrobial, compared to monomicrobial pneumonia. No other significant differences were found between the two groups in the remaining baseline characteristics, comorbidities, reasons for ICU admission, disease severity, and laboratory variables at the onset of pneumonia.

\section{Microbiologic assessment}

The proportions of lower respiratory tract samples processed for microbiology were similar in the two groups (Table 3). However, blood and pleural fluid culture were performed more often in patients with polymicrobial pneumonia, in case of pleural fluid, owing to the higher incidence of pleural effusion in this group.

There were 2 patients $(5 \%)$ in the polymicrobial pneumonia group with methicillin-sensitive Staphylococcus aureus (MSSA) isolated in pleural fluid. In the monomicrobial pneumonia group, 8 patients $(4 \%)$ had positive pleural fluid cultures: MSSA and Pseudomonas aeruginosa in 3 patients, and MRSA in 2 patients.

There were 5 patients (12\%) in the polymicrobial pneumonia group with positive blood cultures: Serratia 


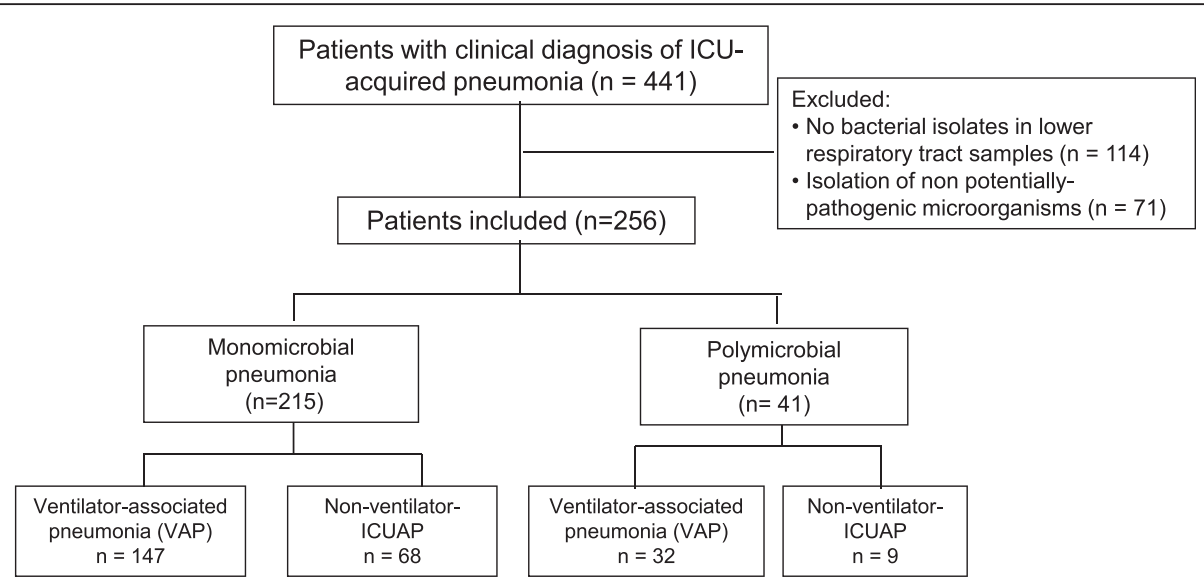

Fig. 1 Trial profile of included and excluded patients. ICU intensive care unit, VAP ventilator-associated pneumonia, ICUAP ICU-acquired pneumonia

Table 1 Baseline characteristics of patients at ICU admission

\begin{tabular}{|c|c|c|c|}
\hline & $\begin{array}{l}\text { Monomicrobial pneumonia } \\
\mathrm{n}=215\end{array}$ & $\begin{array}{l}\text { Polymicrobial pneumonia } \\
\mathrm{n}=41\end{array}$ & $P$ value \\
\hline Age, years & $63 \pm 16$ & $60 \pm 17$ & 0.34 \\
\hline Sex, male, n (\%) & $155(72)$ & $31(76)$ & 0.64 \\
\hline APACHE-II score & $17 \pm 6$ & $18 \pm 6$ & 0.52 \\
\hline SAPS-II score & $41 \pm 15$ & $42 \pm 13$ & 0.66 \\
\hline SOFA score & $7.2 \pm 3.1$ & $7.8 \pm 3.3$ & 0.28 \\
\hline Current or former smokers, n (\%) & $113(53)$ & $20(49)$ & 0.66 \\
\hline Current or former alcohol abuse, n (\%) & $57(27)$ & $10(24)$ & 0.77 \\
\hline \multicolumn{4}{|l|}{ Co-morbidities, n (\%) } \\
\hline Diabetes mellitus & $47(22)$ & $10(24)$ & 0.72 \\
\hline Chronic renal failure & $17(8)$ & $2(5)$ & 0.50 \\
\hline Solid cancer & $41(19)$ & $3(7)$ & 0.068 \\
\hline Chronic heart disorders & $71(33)$ & $6(15)$ & 0.019 \\
\hline Chronic lung disease & $74(34)$ & $10(24)$ & 0.21 \\
\hline Chronic liver disease & $36(17)$ & $8(20)$ & 0.67 \\
\hline Recent surgery, n (\%) & $97(45)$ & $15(37)$ & 0.31 \\
\hline Tracheostomy at admission, n (\%) & $24(11)$ & $4(10)$ & 0.78 \\
\hline \multicolumn{4}{|l|}{ Main causes of ICU admission, $\mathrm{n}(\%)$} \\
\hline Postoperative & $38(18)$ & $4(10)$ & 0.31 \\
\hline Hypoxemic respiratory failure & $37(17)$ & $7(17)$ & 0.85 \\
\hline Decreased consciousness & $31(14)$ & $8(20)$ & 0.56 \\
\hline Hypercapnic respiratory failure & $26(12)$ & $2(5)$ & 0.28 \\
\hline Cardiac arrest & $15(7)$ & $4(10)$ & 0.77 \\
\hline Septic shock & $17(8)$ & $3(7)$ & 0.85 \\
\hline Multiple trauma & $18(8)$ & $6(15)$ & 0.34 \\
\hline Non-surgical abdominal disease & $10(5)$ & $3(7)$ & 0.75 \\
\hline Previous antibiotics in the ICU, $\mathrm{n}(\%)$ & $163(76)$ & $31(76)$ & 0.98 \\
\hline Previous cardiopulmonary resuscitation, n (\%) & $23(11)$ & $4(10)$ & 0.86 \\
\hline
\end{tabular}

APACHE acute physiology and chronic health evaluation; SAPS simplified acute physiology score; SOFA sepsis-related organ failure assessment; ICU intensive care unit 
Table $\mathbf{2}$ Characteristics of patients at onset of pneumonia

\begin{tabular}{|c|c|c|c|}
\hline & $\begin{array}{l}\text { Monomicrobial pneumonia } \\
n=215\end{array}$ & $\begin{array}{l}\text { Polymicrobial pneumonia } \\
n=41\end{array}$ & $P$ value \\
\hline Ventilator-associated pneumonia, n (\%) & $147(68)$ & $32(78)$ & 0.22 \\
\hline Non-ventilator-ICUAP, n (\%) & $68(32)$ & $9(22)$ & \\
\hline Early-onset pneumonia, n (\%) & $55(26)$ & $14(34)$ & 0.27 \\
\hline Late-onset pneumonia, n (\%) & $159(74)$ & $27(66)$ & \\
\hline ICU stay before pneumonia, days & $7 \pm 8$ & $8 \pm 9$ & 0.79 \\
\hline Hospital stay before pneumonia, days & $12 \pm 13$ & $10 \pm 9$ & 0.26 \\
\hline SOFA score & $7.5 \pm 3.4$ & $7.9 \pm 3.0$ & 0.51 \\
\hline CPIS day 1 & $6.4 \pm 1.5$ & $6.9 \pm 1.5$ & 0.026 \\
\hline Previous use of corticosteroids, n (\%) & $81(38)$ & $20(50)$ & 0.14 \\
\hline Previous airway colonization, n (\%) & $87(41)$ & $12(29)$ & 0.18 \\
\hline ARDS criteria, n (\%) & $22(10)$ & $7(18)$ & 0.16 \\
\hline Pleural effusion, n (\%) & $52(25)$ & $20(49)$ & 0.002 \\
\hline Shock at onset of pneumonia, n (\%) & $101(47)$ & $19(46)$ & 0.94 \\
\hline Serum creatinine, mg/Dl & $1.25 \pm 1.04$ & $1.15 \pm 0.90$ & 0.57 \\
\hline Blood hemoglobin, g/L & $10.5 \pm 1.7$ & $10.9 \pm 1.9$ & 0.14 \\
\hline White blood cell count, $\mathrm{L}^{-9}$ & $14,068 \pm 7,282$ & $12,510 \pm 4,893$ & 0.19 \\
\hline $\mathrm{PaO}_{2} / \mathrm{FiO}_{2}, \mathrm{mmHg}$ & $210 \pm 82$ & $202 \pm 80$ & 0.56 \\
\hline
\end{tabular}

ICU intensive care uni, ICUAP ICU-acquired pneumonia, SOFA sepsis-related organ failure assessment, CPIS clinical pulmonary infection score, ARDS acute respiratory distress syndrome, $\mathrm{PaO}_{2} / \mathrm{FiO}_{2}$ ratio of arterial oxygen tension to inspired oxygen fraction

spp. in 2 patients, and MSSA, Escherichia coli, and Fusobacterium spp. in 1 patient. The pathogens concomitantly isolated in respiratory samples from these patients with bacteremia were: Serratia spp. (Morganella morganii and MSSA), MSSA (S. pneumoniae), E. coli (MSSA), and Fusobacterium spp. (E. coli). In the monomicrobial pneumonia group, 18 patients $(8 \%)$ had positive blood cultures: $P$. aeruginosa in 4 patients, MRSA and E. coli in 3 patients, MSSA and Klebsiella spp. in 2 patients, and Stenotrophomonas maltophilia, Citrobacter spp., Bacteroides fragilis and Proteus mirabilis in 1 patients.

The etiologic diagnosis of pneumonia is shown in Table 4. All patients with polymicrobial pneumonia had two different pathogens identified, except two who had three different pathogens identified (Table 5). The most frequently isolated pathogens were $P$. aeruginosa, Enterobacteriaceae, and MSSA. Several bacteria, such as MSSA, Haemophilus influenzae,
Klebsiella spp., E. coli, Enterobacter spp., Citrobacter spp., and Serratia spp., were more frequently isolated in patients with polymicrobial pneumonia. The remaining pathogens were isolated at similar rates in both groups. These findings were similar when we analyzed patients with VAP and non-ventilator ICUAP separately.

The proportion of patients with MDR and XDR pathogens isolated were similar in both groups (Table 4). There were no patients with PDR microorganisms. Patients treated with antibiotics before the onset of ICUAP more frequently had MDR or XDR pathogens than those not treated previously with antibiotics (59 (30 \%) vs. 9 (15\%), respectively, $p=0.014)$. A new microbiologic evaluation was done on the third day of evolution in 169 patients (79\%) and 33 patients (80\%) from the monomicrobial and polymicrobial groups, respectively. The microbiologic evolution is shown in Table 4.

Table 3 Diagnostic samples processed for microbiologic culture

\begin{tabular}{llll}
\hline & $\begin{array}{l}\text { Monomicrobial pneumonia } \\
\mathrm{n}=215\end{array}$ & $\begin{array}{l}\text { Polymicrobial pneumonia } \\
\mathrm{n}=41\end{array}$ & $\begin{array}{l}P \text { value } \\
\text { Any lower respiratory tract sample, } \mathrm{n}(\%)\end{array}$ \\
Tracheal aspirate or sputum, $\mathrm{n}(\%)^{\mathrm{a}}$ & $213(99)$ & $41(100)$ & 3.54 \\
Bronchoalveolar lavage, $\mathrm{n}(\%)$ & $202(94)$ & $38(93)$ & 0.76 \\
Pleural fluid culture, $\mathrm{n}(\%)$ & $41(19)$ & $9(22)$ & 0.68 \\
Blood culture, $\mathrm{n}(\%)$ & $18(8)$ & $34(83)$ & 0.009 \\
\hline
\end{tabular}

${ }^{a}$ Sputum or tracheal aspirates were obtained depending on whether or not patients were intubated at onset of pneumonia. In some patients, a sample of both sputum and tracheal aspirate were processed for culture 
Table 4 Etiologic diagnosis of pneumonia

\begin{tabular}{|c|c|c|c|}
\hline Pathogen, n (\%) & $\begin{array}{l}\text { Monomicrobial pneumonia } \\
n=215\end{array}$ & $\begin{array}{l}\text { Polymicrobial pneumonia } \\
n=41\end{array}$ & $P$ value \\
\hline \multicolumn{4}{|l|}{ Gram-positive bacteria } \\
\hline Methicillin-sensitive Staphylococcus aureus & $39(18)$ & $14(34)$ & 0.037 \\
\hline Methicillin-resistant Staphylococcus aureus & $18(8)$ & $3(7)$ & 0.94 \\
\hline Streptococcus pneumoniae & $10(5)$ & $3(7)$ & 0.75 \\
\hline \multicolumn{4}{|l|}{ Gram-negative bacteria } \\
\hline \multicolumn{4}{|l|}{ Enterobacteriaceae } \\
\hline Klebsiella spp. & $14(7)$ & $9(22)$ & 0.005 \\
\hline Escherichia coli & $9(4)$ & $10(24)$ & $<0.001$ \\
\hline Proteus spp. & $3(1)$ & $3(7)$ & 0.087 \\
\hline Enterobacter spp. & $9(4)$ & $6(15)$ & 0.025 \\
\hline Citrobacter spp. & $2(1)$ & $3(7)$ & 0.039 \\
\hline Serratia spp. & $9(4)$ & $6(15)$ & 0.025 \\
\hline Morganella morganii & $1(0.5)$ & $1(2.4)$ & 0.73 \\
\hline Haemophilus influenza & $6(3)$ & $5(12)$ & 0.023 \\
\hline \multicolumn{4}{|l|}{ Non-fermenting Gram-negative bacilli } \\
\hline Stenotrophomonas maltophilia & $12(6)$ & $4(10)$ & 0.51 \\
\hline Pseudomonas aeruginosa & $74(34)$ & $12(29)$ & 0.65 \\
\hline Acinetobacter spp. & 0 & $1(2.4)$ & 0.38 \\
\hline Moraxella catarrhalis & $2(0.9)$ & $1(2.4)$ & 0.98 \\
\hline Fusobacterium spp. & 0 & $1(2.4)$ & 0.38 \\
\hline Bacteroides fragilis & $1(0.5)$ & 0 & 0.36 \\
\hline \multicolumn{4}{|l|}{ Fungi } \\
\hline Aspergillus spp. & $6(3)$ & $2(5)$ & 0.84 \\
\hline Bacteremia & $18(8)$ & $5(12)$ & 0.63 \\
\hline Patients with drug-resistant pathogens: & & & 0.61 \\
\hline MDR pathogens & $38(18)$ & $9(22)$ & \\
\hline XDR pathogens & $19(9)$ & $2(5)$ & \\
\hline \multicolumn{4}{|l|}{ MDR pathogens isolated ${ }^{\mathrm{a}}$ : } \\
\hline Methicillin-resistant S. aureus & 18 & 3 & \\
\hline Non-fermenting Gram-negative bacilli & 12 & 1 & \\
\hline Enterobacteriaceae & 8 & 7 & \\
\hline \multicolumn{4}{|l|}{ XDR pathogens isolated: } \\
\hline Non-fermenting Gram-negative bacilli & 18 & 2 & \\
\hline Enterobacteriaceae & 1 & 0 & \\
\hline \multicolumn{4}{|l|}{ Microbiologic evolution on day 3: } \\
\hline Persistence of 2 pathogens from day 1 & - & $5(12)$ & \\
\hline Persistence of 1 pathogen from day 1 & $74(34)$ & $13(32)$ & \\
\hline Persistence + new pathogen isolated & $12(6)$ & $0(0)$ & \\
\hline Eradication but new pathogen isolated & $12(6)$ & $1(2)$ & \\
\hline Eradication of initial pathogen & $71(33)$ & $14(34)$ & \\
\hline Microbiologic evaluation on day 3 not done & $46(21)$ & $8(20)$ & \\
\hline
\end{tabular}

an two patients with polymicrobial pneumonia, both pathogens were multi-drug-resistant (MDR). XDR extensive-drug-resistant 
Table 5 Combinations of pathogens according to microbial groups in patients with polymicrobial pneumonia

\begin{tabular}{|c|c|}
\hline Pathogens & Number \\
\hline \multicolumn{2}{|l|}{ Patients with 3 pathogens identified } \\
\hline Enterobacteriaceae + MSSA + non-fermenting GNB & 1 \\
\hline Enterobacteriaceae + MSSA + H. influenzae & 1 \\
\hline \multicolumn{2}{|l|}{ Patients with 2 pathogens identified } \\
\hline 2 Enterobacteriaceae & 9 \\
\hline Enterobacteriaceae + MSSA & 6 \\
\hline Enterobacteriaceae + non-fermenting GNB & 6 \\
\hline 2 non-fermenting GNB & 3 \\
\hline Enterobacteriaceae $+\mathrm{H}$. influenzae & 2 \\
\hline Enterobacteriaceae + MRSA & 2 \\
\hline MSSA + S. pneumoniae & 2 \\
\hline MSSA + non-fermenting GNB & 2 \\
\hline Enterobacteriaceae $+M$. catarrhalis & 1 \\
\hline Enterobacteriaceae + Fusobacterium spp & 1 \\
\hline $\mathrm{MSSA}+H$. influenza & 1 \\
\hline MSSA + Aspergillus spp. & 1 \\
\hline Non-fermenting GNB + Aspergillus spp. & 1 \\
\hline Non-fermenting GNB + MRSA & 1 \\
\hline S. pneumoniae $+\mathrm{H}$. influenzae & 1 \\
\hline
\end{tabular}

MSSA methicillin-sensitive Staphylococcus aureus, GNB Gram-negative bacilli, MRSA methicillin-resistant Staphylococcus aureus

\section{Assessment of systemic inflammatory response}

The serum levels of all inflammatory biomarkers were similar in patients from the two groups (Table 6).

\section{Outcome variables}

The appropriateness of the empirical antimicrobial treatment, the initial non-response to treatment, the length of stay, the ventilator-free days, and mortality at 28 and 90 days were similar in both groups (Table 7 and Fig. 2). Mortality of patients adjusted for initial non-response to treatment did not differ between groups (28 days: $p=0.71$; 90 days: $p=0.49$ ).
The most frequent cause of death was shock-multiple organ failure. Even when adjusted for variables potentially related to mortality, the polymicrobial etiology of ICUAP was not associated with 28-day mortality (adjusted hazard ratio 0.86, $95 \%$ confidence interval $0.44-1.58, p=0.65$ ) or 90-day mortality (adjusted hazard ratio $1.16,95 \%$ confidence interval $0.57-2.39, p=0.69$ ).

\section{Discussion}

Polymicrobial etiology accounted for $16 \%$ cases of ICUAP with positive microbiology. Except for less frequent chronic heart disease and more frequent pleural effusion in polymicrobial pneumonia, there were no other significant differences between patients with monomicrobial and polymicrobial pneumonia in their baseline characteristics, inflammatory response or outcomes.

Information about the polymicrobial etiology of ICUAP is limited. The only study that specifically addressed this issue in VAP, published in 2002 [11], found a substantially higher proportion of polymicrobial etiology (48 \%) compared to the present one. Unlike our study, those authors included some bacteria that are considered nonpathogenic for the lung in non-immunosuppressed patients, such as several Streptococcus species, Neisseria spp, Enterococcus spp, and coagulase-negative Staphylococci. Indeed, a substantial proportion of microbial isolates reported in polymicrobial VAP in that study (42\%) represented these types of microbes [11]. Similarly, previous observational studies reported rates of polymicrobial etiology of VAP that ranged between $28 \%$ and $50 \%$ when PPMs and non-pathogenic microbes were analyszed [34-37]. Having included non-pathogenic microbes would have increased the rate of polymicrobial pneumonia to $30 \%$ in our population. Conversely, we report in our study that $16 \%$ of patients with ICUAP had polymicrobial etiology when we restricted the analysis to PPMs. A previous study that used the same criteria reported a similar rate (10\%) for VAP of polymicrobial etiology [38].

A relevant issue in the polymicrobial etiology of ICUAP is the potential prognostic implications. For that reason, finding predictors of polymicrobial pneumonia

Table 6 Serum levels of inflammatory biomarkers

\begin{tabular}{|c|c|c|c|c|c|}
\hline & $N^{a}$ & $\begin{array}{l}\text { Monomicrobial pneumonia } \\
\mathrm{n}=215\end{array}$ & $N^{a}$ & $\begin{array}{l}\text { Polymicrobial pneumonia } \\
n=41\end{array}$ & $P$ value \\
\hline C-reactive protein, $\mathrm{mg} / \mathrm{dL}$ & 206 & $13(7 ; 22)$ & 36 & $13(4 ; 25)$ & 0.75 \\
\hline IL-6 day $1, \mathrm{pg} / \mathrm{mL}$ & 107 & $157(49: 462)$ & 19 & $92(34 ; 213)$ & 0.19 \\
\hline $\mathrm{IL}-8$ day $1, \mathrm{pg} / \mathrm{mL}$ & 107 & $99(59 ; 209)$ & 19 & $69(55 ; 161)$ & 0.33 \\
\hline TNF-alpha day $1, \mathrm{pg} / \mathrm{mL}$ & 107 & $8(5 ; 16)$ & 19 & $7(3 ; 10)$ & 0.30 \\
\hline Procalcitonin day $1, \mathrm{ng} / \mathrm{mL}$ & 108 & $0.48(0.15 ; 1.57)$ & 20 & $0.44(0.06 ; 1.72)$ & 0.53 \\
\hline MR-proADM day $1, \mathrm{nmol} / \mathrm{L}$ & 114 & $1.35(0.55 ; 2.28)$ & 20 & $0.60(0.25 ; 2.02)$ & 0.13 \\
\hline
\end{tabular}

Reported values are median (interquartile range). ${ }^{a}$ Number of patients with samples processed for each inflammatory biomarker in each group. IL interleukin, $M R$-proADM mid-regional pro-adrenomedullin, TNF tumor necrosis factor 
Table 7 Antimicrobial treatment, length of stay and outcomes

\begin{tabular}{llll}
\hline & $\begin{array}{l}\text { Monomicrobial pneumonia } \\
\mathrm{n}=215\end{array}$ & $\begin{array}{l}\text { Polymicrobial pneumonia } \\
\mathrm{n}=41\end{array}$ \\
\hline Appropriate empiric treatment, $\mathrm{n}(\%)$ & $185(86)$ & $39(95)$ & $28(68)$ \\
Initial non-response to treatment, $\mathrm{n}(\%)$ & $115(54)$ & $25 \pm 20$ & 0.11 \\
ICU stay, days & $23 \pm 19$ & $43 \pm 31$ & 0.080 \\
Hospital stay, days & $44 \pm 34$ & $0(0 ; 21)$ & 0.47 \\
Ventilator-free days at day 28 & $11(0 ; 23)$ & & 0.98 \\
Cause of death within 90 days, $\mathrm{n}(\%)$ & & $9(56)$ \\
$\quad$ Shock-multiple organ failure & $65(70)$ & $2(13)$ \\
Refractory hypoxemia & $11(12)$ & 0 \\
Order do-not-resuscitate & $6(7)$ & $4(25)$ \\
Brain anoxia & $8(9)$ & $1(6)$ \\
Other & $2(2)$ & 0.26 \\
\hline
\end{tabular}

ICU intensive care unit

could hypothetically be of potential interest. However, in a clinical setting of highly appropriate initial antibiotic treatment, as reported in the present study for both groups, all the outcomes, including length of stay, ventilator-free days and mortality, were similar in the two groups. Indeed, in our study the numbers of patients with MDR or XDR pathogens in our study did not differ with pneumonia of polymicrobial etiology. In addition, when patients were clustered into non-ventilated ICUAP and VAP, there were also no statistically significant differences in these outcomes.

In our study, the only variables associated with polymicrobial etiology were absence of chronic heart disease and prior hospital admission, and the presence of pleural effusion, which was twice as high in the polymicrobial group. We have previously reported that patients with clinical diagnosis of both community-acquired pneumonia and ICUAP and negative microbiology more frequently have chronic heart disease [14, 39]. Both studies suggested that some of these cases might also represent, at least in part, fluid overload due to congestive heart failure added to the underlying inflammatory process potentially mimicking pneumonia. Similarly, underlying chronic heart disease might hypothetically have contributed to the development of pulmonary congestion in patients with presumably lower bacterial burden, such as those with pneumonia of monomicrobial etiology.

We do not have a clear explanation for the association between a higher rate of pleural effusion and polymicrobial pneumonia. The isolation of MSSA in pleural fluid culture from two patients was not sufficiently decisive to allocate them to the polymicrobial pneumonia group; in one patient, this pathogen was concomitantly identified in blood and tracheal aspirate cultures, while in the other, both $H$. influenzae and Klebsiella spp were isolated in a tracheal aspirate culture. The association between pleural effusion and ICUAP of polymicrobial etiology needs to be confirmed in future prospective studies.

Neither prior antibiotic treatment nor late-onset pneumonia, as in the previous French study [11], were predictors of polymicrobial pneumonia in our study. However, prior antibiotic treatment was associated with the presence of MDR or XDR pathogens in our study. In addition we found no association between the severity of presentation and polymicrobial etiology. This finding complements a previous study in 343 patients with
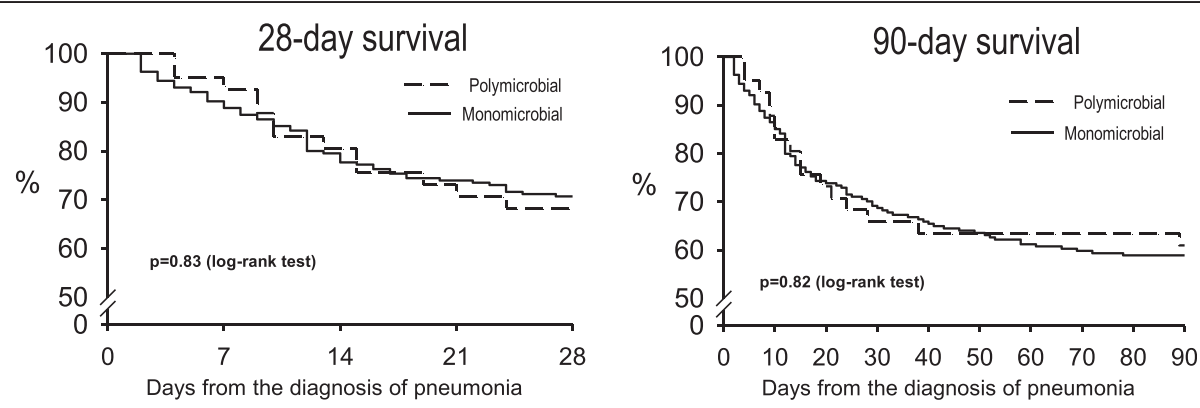

Fig. 2 Kaplan-Meier survival curves at 28 and 90 days in the study cohort survivors in patients with monomicrobial and polymicrobial pneumonia 
ICUAP that concluded that severity of illness seems not to affect etiology [9].

We also found no differences in the serum levels of any inflammatory biomarkers that we measured at the onset of pneumonia. In relation to the etiology of ICUAP, we have recently reported that inflammatory biomarkers were unable to differentiate between patients with positive and negative microbiology [14], or patients with or without MDR pathogens [9]. All these studies confirm that inflammatory biomarkers are not useful in predicting the etiology of ICUAP.

The main strengths of our study are the prospective design, the detailed description of microbiology in ICUAP, the inclusion of both VAP and non-ventilator ICUAP, the exclusion of non-potentially pathogenic microorganisms from the analysis, the assessment of several inflammatory biomarkers, and the follow up of patients up to 90 days. However, in our study we excluded immunosuppressed patients. Consequently, we cannot extrapolate our results to this population.

This study has some limitations. First, it was conducted in a single center, so the extrapolation of these findings to other settings must be done cautiously. Second, we did not use molecular microbiological techniques that are potentially more sensitive. However, the experience of using these techniques in ICUAP, and in non-ventilator ICUAP and VAP, is still scarce. Third, the sample size of our study is not enough large to make a robust analysis of all related questions; when comparing several characteristics between the two groups of patients the current study was underpowered. It is important to outline that this is a non-interventional study and our purpose was only to describe clinical findings. Fourth, there were no adjustments made for multiple comparisons.

\section{Conclusion}

The etiology of ICUAP with microbiologic confirmation was polymicrobial in $16 \%$ of patients. Pleural effusion and absence of chronic heart disease are associated with polymicrobial pneumonia. When empiric antibiotic treatment is frequently appropriate, polymicrobial etiology does not influence the outcome of ICUAP.

\section{Key messages}

- Polymicrobial etiology of ICU-acquired pneumonia accounted for $16 \%$ cases with microbiologic confirmation

- Polymicrobial etiology of ICU-acquired pneumonia was associated with pleural effusion and absence of chronic heart disease

- Polymicrobial etiology did not result in higher incidence of multi-drug- and extensive-drugresistant pathogens
- When empiric treatment is appropriate, polymicrobial etiology does not influence the outcome of ICU-acquired pneumonia

\section{Abbreviations}

APACHE: acute physiology and chronic health evaluation; ARDS: acute respiratory distress syndrome; BAL: bronchoalveolar lavage; CPIS: clinical pulmonary infectious score; ICU: intensive care unit; ICUAP: ICU-acquired pneumonia; L: interleukin; MDR: multi-drug-resistant; MRSA: methicillin-resistant Staphylococcus aureus; MSSA: methicillin-sensitive Staphylococcus aureus; $\mathrm{PaO}_{2} / \mathrm{FiO}_{2}$ : arterial partial pressure of oxygen/inspired oxygen fraction; PDR: pan-drug resistance; PPM: potentially pathogenic microorganism; SAPS: simplified acute physiology score; SOFA: sepsis-related organ failure assessment; TBAS: tracheobronchial aspirates; TNF: tumor necrosis factor;

VAP: ventilator-associated pneumonia; XDR: extensive-drug-resistant.

\section{Competing interests}

The authors declare that they have no competing interests.

\section{Authors' contributions}

MF participated in the study design, recruitment of patients, data analysis and writing of the manuscript. LFD participated in the study design, recruitment of patients and writing of the manuscript. AL participated in the study design, recruitment of patients and writing of the manuscript. MR participated in recruitment of patients, interpretation of data and critical review of the manuscript. MC participated in recruitment of patients, interpretation of data and critical review of the manuscript. GLB participated in interpretation of data, critical review and writing of the manuscript. AG participated in the data analysis, management of database and, drafting of the manuscript. AT participated in the study design, interpretation of date and critical review and writing of the manuscript. All the authors have read and approved the final version of the manuscript.

\section{Acknowledgements}

Rebeca Domingo, Encarna Moreno and Montserrat Sola participated in the study as research nurses collecting and processing blood and respiratory samples. Dr. I. Rovira, Cardiovascular ICU; Dr. E. Zavala, Surgical ICU; Dr. X. Bosch, Coronary Unit; Dr. P. Castro, Medical ICU; and Dr. A. Escorsell, Hepatology and Gastroenterology ICU, helped with screening and recruitment of patients.

\section{Author details}

${ }^{1}$ Department of Pneumology, Thorax Institute, Hospital Clinic, Villarroel 170, 08036 Barcelona, Spain. ${ }^{2}$ Institut d'Investigacions Biomèdiques August Pi I Sunyer (IDIBAPS), Barcelona, Spain. ${ }^{3}$ Centro de Investigación Biomédica en Red-Enfermedades Respiratorias (CibeRes CB06/06/0028)-Instituto de Salud Carlos III (ISCiii), Madrid, Spain. ${ }^{4}$ Department of Internal Medicine, Ospedale Sant'Andrea, "Sapienza" University, Via di Grottarossa 1035-1039, Rome, Italy. ${ }^{5}$ Sotiria Chest Diseases Hospital, 6rd Respiratory Department, Mesogion 152, Athens, Greece. ${ }^{6}$ Department of Anesthesia, Università degli Studi di Milano, IRCCS Fondazione Ospedale Maggiore Policlinico Cà Granda Milano, Milan, Italy.

Received: 23 October 2015 Accepted: 10 December 2015

Published online: 23 December 2015

\section{References}

1. American Thoracic Society, Infectious Diseases Society Of America. Guidelines for the management of adults with hospital-acquired, ventilator-associated, and healthcare-associated pneumonia. Am J Respir Crit Care Med. 2005;171: 388-416.

2. Esperatti M, Ferrer M, Theessen A, Liapikou A, Valencia M, Saucedo LM, et al. Nosocomial pneumonia in the intensive care unit acquired during mechanical ventilation or not. Am J Respir Crit Care Med. 2010;182:1533-9.

3. Burgmann H, Hiesmayr JM, Savey A, Bauer P, Metnitz B, Metnitz PP. Impact of nosocomial infections on clinical outcome and resource consumption in critically ill patients. Intensive Care Med. 2010;36:1597-601.

4. Wg M, Mm R, Groenwold R, Dc B, Camus C, Bauer TT, et al. Attributable mortality of ventilator-associated pneumonia: a meta-analysis of individual patient data from randomised prevention studies. Lancet Infect Dis. 2013;13:665-71. 
5. Alvarez-Lerma F. Modification of empiric antibiotic treatment in patients with pneumonia acquired in the intensive care unit. ICU-Acquired Pneumonia Study Group. Intensive Care Med. 1996;22:387-94.

6. Ms N, Soulountsi V. De-escalation therapy: is it valuable for the management of ventilator-associated pneumonia? Clin Chest Med. 2011;32:517-34.

7. Kumar A, Zarychanski R, Light B, Parrillo J, Maki D, Simon D, et al. Early combination antibiotic therapy yields improved survival compared with monotherapy in septic shock: a propensity-matched analysis. Crit Care Med. 2010;38:1773-85.

8. Dk H, Dodek P, Muscedere J, Day A, Cook D. Randomized trial of combination versus monotherapy for the empiric treatment of suspected ventilator-associated pneumonia. Crit Care Med. 2008;36:737-44.

9. Di Pasquale M, Ferrer M, Esperatti M, Crisafulli E, Giunta V, Li Bassi G, et al. Assessment of severity of ICU-acquired pneumonia and association with etiology. Crit Care Med. 2014;42:303-12

10. Blot S, Koulenti D, Dimopoulos G, Martin C, Komnos A, Krueger WA, et al. Prevalence, risk factors, and mortality for ventilator-associated pneumonia in middle-aged, old, and very old critically ill patients*. Crit Care Med. 2014;42:601-9.

11. Combes A, Figliolini C, Trouillet JL, Kassis N, Wolff M, Gibert C, et al. Incidence and outcome of polymicrobial ventilator-associated pneumonia. Chest. 2002:121:1618-23.

12. Kohlenberg A, Schwab F, Behnke M, Geffers C, Gastmeier P. Pneumonia associated with invasive and noninvasive ventilation: an analysis of the german nosocomial infection surveillance system database. Intensive Care Med. 2010;36:971-8.

13. Karhu J, Ala-Kokko TI, Ylipalosaari P, Ohtonen P, Laurila JJ, Syrjala H. Hospital and long-term outcomes of ICU-treated severe community- and hospitalacquired, and ventilator-associated pneumonia patients. Acta Anaesthesiol Scand. 2011;55:1254-60.

14. Giunta V, Ferrer M, Esperatti M, Ranzani O, Saucedo LM, Bassi GL, et al. ICU-acquired pneumonia with or without etiologic diagnosis: a comparison of outcomes. Crit Care Med. 2013:41:2133-43.

15. Fabregas N, Ewig S, Torres A, El Ebiary M, Ramirez J, De La Bellacasa JP, et al. Clinical diagnosis of ventilator associated pneumonia revisited: comparative validation using immediate post-mortem lung biopsies. Thorax. 1999;54:867-73.

16. Woodhead MA, Torres A. Definition and Classification of Community-Acquired and Nosocomial Pneumonias. In: Torres A, Woodhead M, editors. Pneumonia. Sheffield: European Respiratory Society Journals Ltd; 1997. p. 1-12.

17. Meduri GU, Chastre J. The standardization of bronchoscopic techniques for ventilator-associated pneumonia. Chest. 1992;102:557s-64.

18. Kollef $M, K r$ B, Rd R, Ml H. The safety and diagnosis accuracy of minibronchoalveolar lavage in patients with suspected ventilator associated pneumonia. Ann Intern Med. 1995;122:743-8.

19. Ruiz M, Torres A, Ewig S, Marcos MA, Alcón A, Lledó R, et al. Noninvasive versus invasive microbial investigation in ventilator-associated pneumonia: evaluation of outcome. Am J Respir Crit Care Med. 2000;162:119-25.

20. Ioanas M, Cavalcanti M, Ferrer M, Valencia M, Agusti C, Puig De La Bellacasa $J$, et al. Hospital-acquired pneumonia: coverage and treatment adequacy of current guidelines. Eur Respir J. 2003;22:876-82.

21. Am V, Ma T, Oj I, Lf A, Jn C, Cm H, et al. Diagnostic value of quantitative cultures of endotracheal aspirate in ventilator-associated pneumonia: a multicenter study. Arch Bronconeumol. 2003;39:394-9.

22. Martin-Loeches I, Torres A, Rinaudo M, Terraneo S, De Rosa F, Ramirez P, et al. Resistance patterns and outcomes in intensive care unit (ICU)-acquired pneumonia. Validation of European Centre for Disease Prevention and Control (ECDC) and the Centers for Disease Control and Prevention (CDC) classification of multidrug resistant organisms. J Infect. 2015;70:213-22.

23. Ioanas M, Ferrer M, Cavalcanti M, Ferrer R, Ewig S, Filella X, et al. Causes and predictors of non-response to treatment of the icu-acquired pneumonia. Crit Care Med. 2004;32:938-45

24. Esperatti M, Ferrer M, Giunta V, Ranzani O, Saucedo LM, Li Bassi G, et al. Validation of predictors of adverse outcomes in hospital-acquired pneumonia in the ICU*. Crit Care Med. 2013;41:2151-61.

25. Ramirez P, Ferrer M, Marti V, Reyes S, Martinez R, Menendez R, et al. Inflammatory biomarkers and prediction for intensive care unit admission in severe community-acquired pneumonia. Crit Care Med. 2011;39:2211-7.

26. Bello S, Lasierra AB, Minchole E, Fandos S, Ruiz M, Vera E, et al. Prognostic power of proadrenomedullin in community-acquired pneumonia is independent of aetiology. Eur Respir J. 2012;39:1144-55.

27. Wa K, Ea D, Dp W, Je Z. APACHE II: a severity of disease classification system. Crit Care Med. 1985;13:818-29.
28. Gall Jr L, Lemeshow S, Saulnier F. A new Simplified Acute Physiology Score (SAPS II) based on a European/North American multicenter study. JAMA. 1993;270:2957-63.

29. Cm L, Blanzaco D, Niederman MS, Matarucco W, Baredes NC, Desmery P, et al. Resolution of ventilator-associated pneumonia: prospective evaluation of the clinical pulmonary infection score as an early clinical predictor of outcome. Crit Care Med. 2003;31:676-82.

30. JI V, Moreno R, Takala J, Willatts S, De Mendonca A, Bruining H, et al. The SOFA (Sepsis-related Organ Failure Assessment) score to describe organ dysfunction/failure. On behalf of the Working Group on Sepsis-Related Problems of the European Society of Intensive Care Medicine. Intensive Care Med. 1996;22:707-10.

31. Rp D, Mm L, Jm C, Bion J, Parker MM, Jaeschke $R$, et al. Surviving Sepsis Campaign: International guidelines for management of severe sepsis and septic shock: 2008. Crit Care Med. 2008:36:296-327.

32. Vm R, Gd R, Thompson B, Nd F, Caldwell E, Fan E, et al. Acute respiratory distress syndrome: the Berlin Definition. JAMA. 2012;307:2526-33.

33. Da $\mathrm{S}, \mathrm{Gr}$ B. Statistical evaluation of ventilator-free days as an efficacy measure in clinical trials of treatments for acute respiratory distress syndrome. Crit Care Med. 2002;30:1772-7.

34. Jy F, Chastre J, Domart Y, Trouillet JL, Pierre J, Darne C, et al. Nosocomial pneumonia in patients receiving continuous mechanical ventilation. Prospective analysis of 52 episodes with use of a protected specimen brush and quantitative culture techniques. Am Rev Respir Dis. 1989;139:877-84.

35. Jj R, Martin De Lassale E, Poete P, Nicolas MH, Bodin L, Jarvier V, et al. Nosocomial bronchopneumonia in the critically ill: Histologic and bacteriologic aspects. Am Rev Respir Dis. 1992;146:1059-66.

36. Jimenez P, Torres A, Rodriguez RR, De-La-Bellacasa JP, Aznar R, Gatell JM, et al. Incidence and etiology of pneumonia acquired during mechanical ventilation. Crit Care Med. 1989;17:882-5.

37. JI T, Chastre J, Vuagnat A, Joly-Guillou ML, Combaux D, Dombret MC, et al. Ventilator-associated pneumonia caused by potentially drug-resistant bacteria. Am J Respir Crit Care Med. 1998;157:531-9.

38. Papazian L, Bregeon F, Thirion X, Gregoire R, Saux P, Denis JP, et al. Effect of ventilator-associated pneumonia on mortality and morbidity. Am J Respir Crit Care Med. 1996;154:91-7

39. Ewig S, Torres A, Angeles MM, Angrill J, Rano A, De Roux A, et al. Factors associated with unknown aetiology in patients with community-acquired pneumonia. Eur Respir J. 2002;20:1254-62.

\section{Submit your next manuscript to BioMed Central and we will help you at every step:}

- We accept pre-submission inquiries

- Our selector tool helps you to find the most relevant journal

- We provide round the clock customer support

- Convenient online submission

- Thorough peer review

- Inclusion in PubMed and all major indexing services

- Maximum visibility for your research

Submit your manuscript at www.biomedcentral.com/submit

Biomed Central 